\title{
Increased SLC7A8 expression mediates L-DOPA uptake by renal tubular epithelial cells
}

\author{
YIHAO WU $^{1 *}$, QIQI YIN ${ }^{2 *}$, SU LIN $^{1}$, XIAOYAN HUANG ${ }^{3}$, \\ QUAN XIA $^{3}$, ZHE CHEN $^{3}$, XINGWEI ZHANG $^{3}$ and DEYE YANG ${ }^{3}$ \\ ${ }^{1}$ Division of Cardiology, The First Affiliated Hospital of Wenzhou Medical University, Wenzhou, Zhejiang 325000; \\ ${ }^{2}$ Department of Internal Medicine, The Third People's Hospital at Anji, Huzhou, Zhejiang 313301; ${ }^{3}$ Division of \\ Cardiology, The Affiliated Hospital of Hangzhou Normal University, Hangzhou, Zhejiang 310015, P.R. China
}

Received January 24, 2016; Accepted January 17, 2017

DOI: $10.3892 / \mathrm{mmr} .2017 .6620$

\begin{abstract}
The kidney serves a central role in the control of blood pressure through the release of vasoactive substances and the urinary excretion of $\mathrm{Na}^{+}$. Patients with essential hypertension usually exhibit persistent high blood pressure accompanied by $\mathrm{Na}^{+}$retention. L-dihydroxyphenylalanine (L-DOPA) is an amino acid, converted by the enzyme aromatic L-amino acid decarboxylase to dopamine. The uptake of L-DOPA by cells of the proximal tubular epithelium of the kidney is controlled by the L-type amino acid transporter 2 (LAT2). LAT2 belongs to the solute carrier family 7 (SLC7) of amino acid transporters and is coded by the SLC7A8 gene. SLC7A8 expression is increased in the second-order mesenteric arteries and kidneys of spontaneously hypertensive rats. The present study aimed to investigate the physiological role of the SLC7A8 gene in L-DOPA handling by kidney cells. Selective upregulation of SLC7A8 mRNA and protein levels was achieved by adenoviral transduction of NRK-52E cells, which retain several properties of proximal tubular epithelial cells. In addition, L-DOPA uptake was determined using high performance liquid chromatography; NRK-52E cells expressing SLC7A8 exhibited increased uptake of L-DOPA. The results of the present study suggested that SLC7A8 may serve a critical role in blood pressure control through regulating L-DOPA uptake in renal epithelial cells of the proximal tubule.
\end{abstract}

Correspondence to: Professor Deye Yang, Division of Cardiology, The Affiliated Hospital of Hangzhou Normal University, 126 Wenzhou Road, Gongshu, Hangzhou, Zhejiang 310015, P.R. China

E-mail: deyeyang203@hotmail.com

*Contributed equally

Key words: hypertension, L-DOPA, SLC7A8, kidney, LAT2

\section{Introduction}

Hypertension is a major health concern, since it can increase the risk for acute vascular events, including myocardial and cerebral infarction. According to the Chinese Hypertension League 2009 report, the prevalence of hypertension in the Chinese population is high, affecting one out of five individuals, i.e. $>2$ billion (1). In the kidney, dopamine receptors serve a pivotal role in blood pressure regulation. Dysfunctional dopamine receptors may increase the severity of essential hypertension. Dopamine is synthesized by the dehydration of the amino acid tyrosine to L-dihydroxyphenylalanine (L-DOPA), which is catalyzed by tyrosine hydroxylase, and the subsequent decarboxylation of L-DOPA, which is catalyzed by aromatic L-amino acid decarboxylase. The kidney does not express tyrosine hydroxylase; however, it can absorb circulating L-DOPA (2). Renal epithelial cells absorb L-DOPA through the $\mathrm{Na}^{+}$-independent and $\mathrm{pH}$-sensitive L-type amino acid transporter type 2 (LAT2). L-DOPA uptake through LAT2 increases with the elevation of blood pressure (3). The structure of LAT2 consists of two polypeptides, the light-chain subunit solute carrier family 7, member 8 (SLC7A8) and the heavy-chain subunit solute carrier family 3 , member 2 (4). SLC7A8, which is responsible for the uptake of L-DOPA, is a non-glycosylated 12-transmembrane-spanning membrane protein, and a member of the SLC superfamily of amino acid transporters (5). It has previously been reported that gene expression differs between spontaneously hypertensive rats (SHR) and their normotensive controls, Wistar Kyoto (WKY) rats, with 19 genes being markedly upregulated in SHR (6). Previous studies have demonstrated that the production and secretion of dopamine is significantly higher in SHR compared with in WKY rats $(7,8)$. Renal dopamine synthesis has been reported to increase in SHR, possibly as a result of the deficiency in dopamine-mediated natriuresis, which has previously been demonstrated in aged Fischer 344 rats (9).

The present study evaluated the expression of L-DOPA transporters in SHR and WKY rats, and investigated the mechanism underlying the increased dopamine synthesis and uptake in renal epithelial cells of the proximal tubule. 


\section{Materials and methods}

Animals. SHR and WKY rats were purchased from Shanghai SLAC Laboratory Animal Co., Ltd. (Shanghai, China). All rats were allowed to acclimate for 1 week prior to experimentation. Male 13-week old rats (weight, 370-390 g) were chosen for the present experiments ( $\mathrm{n}=5$ rats/group). All rats were housed in a specific pathogen-free laboratory animal room under the following conditions: Temperature, $18-29^{\circ} \mathrm{C}$; relative humidity, $40-70 \% ; 12 \mathrm{~h}$ light/dark cycle. All rats received standard rat chow and water ad libitum. All experimental procedures were approved by the Animal Research Committee of Wenzhou Medical University (Wenzhou, China).

Cell cultures. The rat renal epithelial cell line NRK-52E was purchased from the Cell Resource Center of the Shanghai Institutes for Biological Sciences of the Chinese Academy of Sciences (Shanghai, China). Cells were cultured in Dulbecco's modified Eagle's medium (Thermo Fisher Scientific, Inc., Waltham, MA, USA) supplemented with $5 \%$ fetal bovine serum (Thermo Fisher Scientific, Inc.), containing 1\% penicillin and streptomycin. Cells were maintained in an incubator at $37^{\circ} \mathrm{C}$ in a $5 \% \mathrm{CO}_{2}$ atmosphere.

Blood pressure measurements. Pentobarbital $(30 \mathrm{mg} / \mathrm{kg}$ weight) was used to anesthetize the rats. Systolic blood pressure was measured in the arteria caudalis using the MedLab Version 5.0 Bio-signal collect-processing system (Nanjing MedEase Science and Technology Co., Ltd., Nanjing, China). Measurements were repeated three times for each rat and the average blood pressure was noted.

Reverse transcription-quantitative polymerase chain reaction $(R T-q P C R)$. All rats were sacrificed by cervical dislocation, and kidney tissues were collected and maintained in liquid nitrogen. The kidney samples were ground, and total RNA was extracted from a 1:1 mix of kidneys and second-order mesenteric artery samples, as well as NRK-52E cells using TRIzol ${ }^{\circledR}$ (Invitrogen; Thermo Fisher Scientific, Inc.) according to the manufacturer's protocol. Total RNA $(1 \mu \mathrm{g})$ was reverse transcribed into cDNA using Revert Aid $^{\mathrm{TM}}$ First Strand cDNA Synthesis kit (cat. no. K1622; Thermo Fisher Scientific, Inc.) at $42^{\circ} \mathrm{C}$ for $60 \mathrm{~min}$; cDNA was stored at $-70^{\circ} \mathrm{C}$. qPCR analysis was performed on cDNA using SYBR Green PCR Master Mix (Applied Biosystems; Thermo Fisher Scientific, Inc.) in a $20 \mu 1$ reaction volume consisting of $10 \mu \mathrm{l}$ SYBR Green Mix, $1 \mu \mathrm{l}$ forward/reverse primers and 0.5-1 $\mu \mathrm{g}$ template; volume was made up to $20 \mu \mathrm{l}$ with water. The following primers were used for RT-qPCR of targeted gene expression: SLC7A8, forward 5'-CTCCAC TGGAAA AAAGGTAGCA-3', reverse 5'-TGGTGAATG AAGCCACATCTG-3'; and GAPDH, forward, 5'-TCCTGC ACCACCAACTGCTTAG-3' and reverse, 5'-AGTGGC AGTGATGGCATGGACT-3'. The amplification conditions were as follows: Initial cycle at $50^{\circ} \mathrm{C}$ for $2 \mathrm{~min}$ and $95^{\circ} \mathrm{C}$ for $2 \mathrm{~min}$, followed by 40 cycles of denaturation at $95^{\circ} \mathrm{C}$ for $15 \mathrm{sec}$, and 40 cycles of annealing and extension at $59^{\circ} \mathrm{C}$ for 1 min. RT-qPCR was performed using an ABI Prism 7900 Sequence Detector (Applied Biosystems; Thermo Fisher Scientific, Inc.) according to the manufacturer's protocol.
The PCR products were separated by $1.2 \%$ agarose gel electrophoresis (Sigma-Aldrich; Merck KGaA, Darmstadt, Germany), stained with GoldView (Beijing Solarbio Science $\&$ Technology Co., Ltd., Beijing, China) and observed using the Image Master VDS-CL gel-imaging system (Amersham; GE Healthcare Life Sciences, Tokyo, Japan). Relative expression levels of SLC7A8 mRNA were calculated using the $2^{-\Delta \Delta C q}$ method (10); the results were normalized to GAPDH mRNA expression.

Construction of rat SLC7A8 recombinant adenoviral vector. cDNA from rats was amplified by PCR using the primer specific for rat SLC7A8 (forward 5'-GCTGTCACTTTTAGAGCC TAGGAG-3' and reverse 5'-CAGGGATACAGGGCAGAA AGGATGA-3'). PCR was performed using PrimeSTAR ${ }^{\circledR} \mathrm{HS}$ DNA Polymerase (Takara Biotechnology Co., Ltd., Dalian, China) for SLC7A8. Amplification conditions were as follows: Hot start for 5 min at $94^{\circ} \mathrm{C}, 35$ cycles of denaturation $\left(98^{\circ} \mathrm{C}\right.$ for $10 \mathrm{sec})$, annealing $\left(57.8^{\circ} \mathrm{C}\right.$ for $\left.15 \mathrm{sec}\right)$ and extension $\left(72^{\circ} \mathrm{C}\right.$ for $2 \mathrm{~min}$ ), and a final extension step at $72^{\circ} \mathrm{C}$ for $5 \mathrm{~min}$. The PCR products were gel purified using a PCR Clean-Up kit (Sigma-Aldrich; Merck KGaA), according to the manufacturer's protocol, and cloned into pGEM-T Easy vector using T4 DNA ligase (Promega Corporation, Madison, WI, USA). The connection product (pGEM-T Easy vector containing the PCR product) was subsequently transformed into DH5 $\alpha$ Escherichia coli cells (BioVector Science Lab, Inc., Beijing, China) according to the manufacturer's protocol, named T-SLC7A8. NotI restriction enzyme was used to digest the adenovirus shuttle plasmid pShuttle-CMV-green fluorescent protein (GFP) (Shanghai GenePharma Co., Ltd., Shanghai, China) and T-SLC7A8, the SLC7A8 coding sequence, and the vector was linked with T4 DNA ligase, resulting in formation of pShuttle-SLC7A8. Linearized pShuttle-SLC7A8 was dephosphorylated using calf intestinal alkaline phosphatase [New England Biolabs (Beijing) Ltd., Beijing, China] and was transfected into Bj5183 competent cells (Shanghai Weidi Biotechnology Co., Ltd., Shanghai, China), which contain the skeleton plasmid pAdEasy-1 and a homologous recombination enzyme. Following recombination, the correct plasmid, pAdxsi-GFP-SLC7A8, was identified and obtained. pAdxsi-GFP-SLC7A8 was transfected into HEK293 cells (Cell Resource Center of the Shanghai Institutes for Biological Sciences of the Chinese Academy of Sciences, Shanghai, China) using Lipofectamine 2000 (Thermo Fisher Scientific, Inc.) for $24 \mathrm{~h}$. GFP expression was used to confirm successful transfection. After 7-10 days, cells were collected and underwent freeze-thaw cycles at -80 and $37^{\circ} \mathrm{C}$. The viral supernatant was obtained by centrifugation $\left(12,000 \mathrm{xg}\right.$ for $\left.5 \mathrm{~min}, 4^{\circ} \mathrm{C}\right)$ and viral titer was determined for successful transduction.

Adenoviral vector transduction ( $p A d x s i-G F P-S L C 7 A 8)$. The recombinant adenoviral vector (pAdxsi-GFP-SLC7A8) was transduced into NRK-52E cells directly using various viral titers without any transfection media, between $10^{6} \mathrm{PFU} / \mathrm{ml}$ and $10^{8} \mathrm{PFU} / \mathrm{ml}$. Blank control (BC) cells were untransduced; negative control (NC) cells were transduced with the empty pAdxsi adenoviral vector. A total of $48 \mathrm{~h}$ post-transduction, cells were digested by trypsin $(0.05 \%)$ for $5 \mathrm{~min}$ at room temperature. Subsequently, cells were scraped, centrifuged $(1,000 \mathrm{x}$ g for 
5 min at $4^{\circ} \mathrm{C}$ ) and resuspended in PBS; transduction efficiency was confirmed using flow cytometry (BD FACSCalibur; BD Biosciences, San Jose, CA, USA). RNA and protein were then extracted from the cells.

Western blot analysis. A total of $48 \mathrm{~h}$ post-transduction, total protein was isolated from NRK-52E cells. Cells were homogenized in a radioimmunoprecipitation assay lysis buffer with phenylmethanesulfonyl fluoride; the buffer contained $50 \mathrm{mM}$ Tris, $150 \mathrm{mM} \mathrm{NaCl}, 0.1 \%$ sodium dodecyl sulfate and protease inhibitor. Total protein concentration was determined using a bicinchoninic acid protein assay kit (Pierce; Thermo Fisher Scientific, Inc.) according to the manufacturer's protocol. Equal amounts of extracted protein samples (50-80 $\mu \mathrm{g})$ were separated by $10 \%$ SDS-PAGE and transferred onto a polyvinylidene difluoride membrane. The membrane was blocked in 5\% skim milk and 0.5\% Tween-20 for $2.5 \mathrm{~h}$ at room temperature. Subsequently, blots were incubated with anti-SLC7A8 primary antibody (1:1,000; cat. no. ARP43930_T100; AVIVA Systems Biology, Co., San Diego, CA, USA) at $4^{\circ} \mathrm{C}$ overnight and secondary antibody (1:5,000; cat. no. ab6721; Abcam, Cambridge, UK) at $37^{\circ} \mathrm{C}$ for $2 \mathrm{~h}$. GAPDH was used as a loading control $(1: 1,0000$; cat. no. ab181602; Abcam). The bands were visualized using the Image Master VDS-CL gel-imaging system (Amersham; GE Healthcare Life Sciences) and analyzed by Quantity One software version 4.6.2 (Bio-Rad Laboratories, Inc., Hercules, CA, USA).

L-DOPA uptake. After aspirating the culture medium, cell monolayers were pre-incubated for 30 min in Hanks' medium (Thermo Fisher Scientific, Inc.) at $37^{\circ} \mathrm{C}$. In saturation experiments, cells were incubated with $300 \mu \mathrm{l} \mathrm{L-DOPA}(1 \mu \mathrm{g} / \mathrm{ml}$; (Toronto Research Chemicals, Inc., North York, ON, Canada) for 6 min with increasing concentrations of SLC7A8 vector $(100,300$ and $1,000 \mathrm{ng} / \mathrm{ml})$ in $1 \mathrm{ml}$ PBS. In time-course studies, cells were incubated with $1,000 \mathrm{ng} / \mu 1$ SLC7A8 vector and $300 \mu \mathrm{l}$ L-DOPA $(1 \mu \mathrm{g} / \mathrm{ml})$ in $1 \mathrm{ml}$ PBS for $3,6,12,30$ and $60 \mathrm{~min}$. The experiments were terminated by the rapid removal of the uptake solution, followed by a rapid wash with cold PBS. The cells were collected and permeabilized by repeated freeze-thaw cycles. L-DOPA uptake was analyzed using reverse-phase high performance liquid chromatography (HPLC; Agilent Technologies, Santa Clara, CA, USA). Chromatographic conditions: Sample volume, $10 \mu \mathrm{l}$; Column YWG C18 4.6x250 mm, $10 \mu \mathrm{m} \mathrm{C18}$; the mobile phase consisted of $0.05 \mathrm{~mol} / \mathrm{l}$ citric acid (Merck KGaA, Darmstadt, Germany), $0.05 \mathrm{~mol} / \mathrm{l}$ sodium acetate (Shanghai Shenggong Biology Engineering Technology Service, Ltd., Shanghai, China), 5 mmol/1 ethylamine (Shanghai Shenggong Biology Engineering Technology Service, Ltd.), 0.2 mmol/1 EDTA (Merck KGaA), $\mathrm{pH}$ 3.6; flow rate, $0.5 \mathrm{ml} / \mathrm{min}$; detector working potential, $0.7 \mathrm{~V}$; sensitivity, $5 \mathrm{nA}$. The standard curve was constructed using L-DOPA standards (Toronto Research Chemicals, Inc.).

Statistical analysis. The statistical significance of the difference between groups was assessed by one-way analysis of variance, followed by a post hoc Cochran's Q-test, or a Kruskal-Wallis test for non-parametric data, followed by a post hoc Nemenyi test for multiple comparisons. Data are expressed as the mean \pm standard deviation. $\mathrm{P}<0.05$ was considered to indicate a statistically significant difference. Analyses were performed using SPSS software version 18.0 (SPSS, Inc., Chicago, IL, USA).

\section{Results}

Gene expression arrays in SHR and WKY rats. A previous study measured gene expression in SHR and WKY rats by microarray analysis of 10,000 genes (6). A total of 38 genes of interest were detected, including those coding for signal transducers, cell cycle mediators, metabolic enzymes and transcription factors. In the present study, as verified by RT-qPCR, the expression of SLC7A8 in SHR kidneys and second-order mesenteric arteries was significantly increased $(\mathrm{P}<0.01)$ compared with in the WKY group (Fig. 1).

SLC7A8 expression in NRK-52E cells. A 1,819 bp cDNA fragment was isolated by RT-qPCR and inserted into a pGEM-T Easy vector. The full SLC7A8 gene was successfully cloned into a pShuttle-CMV-GFP plasmid and packaged into a pAdxsi adenoviral vector. The successful insertion of the target sequence was confirmed by enzyme digestion analysis and sequencing (Fig. 2). The recombinant adenoviral vector (pAdxsi-GFP-SLC7A8) was transduced into NRK-52E cells. Transduction efficiency was confirmed using flow cytometry (Fig. 3). Considering the cytotoxicity and transduction efficiency, a viral titer of $10^{7} \mathrm{PFU} / \mathrm{ml}$ was chosen. The mRNA and protein expression levels of SLC7A8 were significantly increased in pAdxsi-GFP-SLC7A8-transduced NRK-52E cells $(\mathrm{P}<0.01)$ compared with in the $\mathrm{NC}$ and $\mathrm{BC}$ cells (Figs. 4 and 5).

L-DOPA uptake in transduced NRK-52E cells. When analyzing samples under the same conditions and using the standard curve (Fig. 6), L-DOPA was absorbed by NRK-52E cells co-incubated with L-DOPA and various doses of SLC7A8 for $6 \mathrm{~min}$. The linear range is $100-10,000 \mathrm{ng} / \mathrm{ml}$. The uptake of L-DOPA in NRK-52E cells transduced with the SLC7A8 gene progressively increased with the dose of SLC7A8, whereas no increase in uptake was apparent in the blank or negative control cells (Fig. 7). The results of the time-course studies revealed that the uptake of L-DOPA in NRK-52E cells overexpressing the SLC7A8 gene increased with incubation time, whereas L-DOPA uptake did not appear to be increased in the blank or negative control cells (Fig. 8).

\section{Discussion}

Essential hypertension is a chronic disease in humans. It has previously been reported that gene expression differs between SHR and WKY rats, whereas 19 genes have been identified as being markedly upregulated in SHR (6). Therefore, it may be hypothesized that these genes are associated with essential hypertension. The upregulated genes have been reported to participate in several cellular processes, including $\mathrm{Ca}^{2+}$ homeostasis $(11,12)$, hydrogen peroxide metabolism (13), signal transduction, cell cycle control, cellular proliferation and migration. They may also be involved in pathophysiological processes, such as tissue fibrosis $(14,15)$. In the present study, 


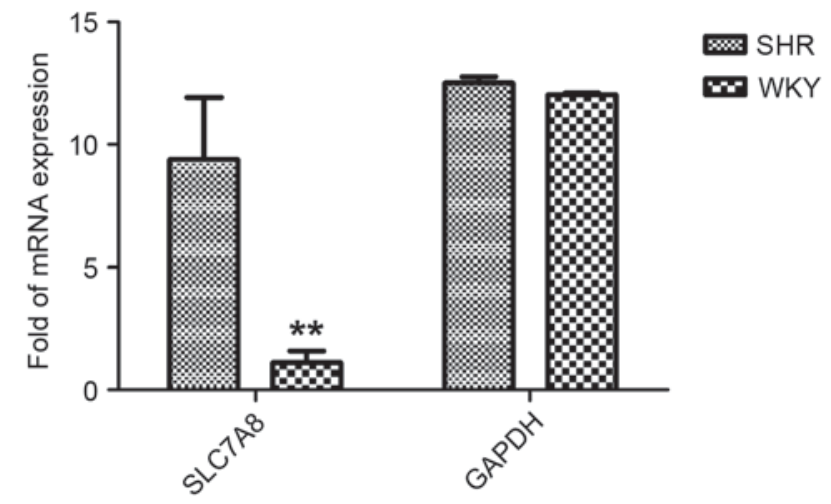

Figure 1. SLC7A8 gene expression was investigated in the kidneys of SHR and WKY rats using reverse transcription-quantitative polymerase chain reaction. GAPDH was used as an internal control gene for RT-qPCR. Data are expressed as the mean \pm standard deviation, $n=3$. ${ }^{* *} \mathrm{P}<0.01$ compared with the SHR group. SHR, spontaneously hypertensive rats; WKY, Wistar Kyoto; SLC7A8, solute carrier family 7 member 8 .

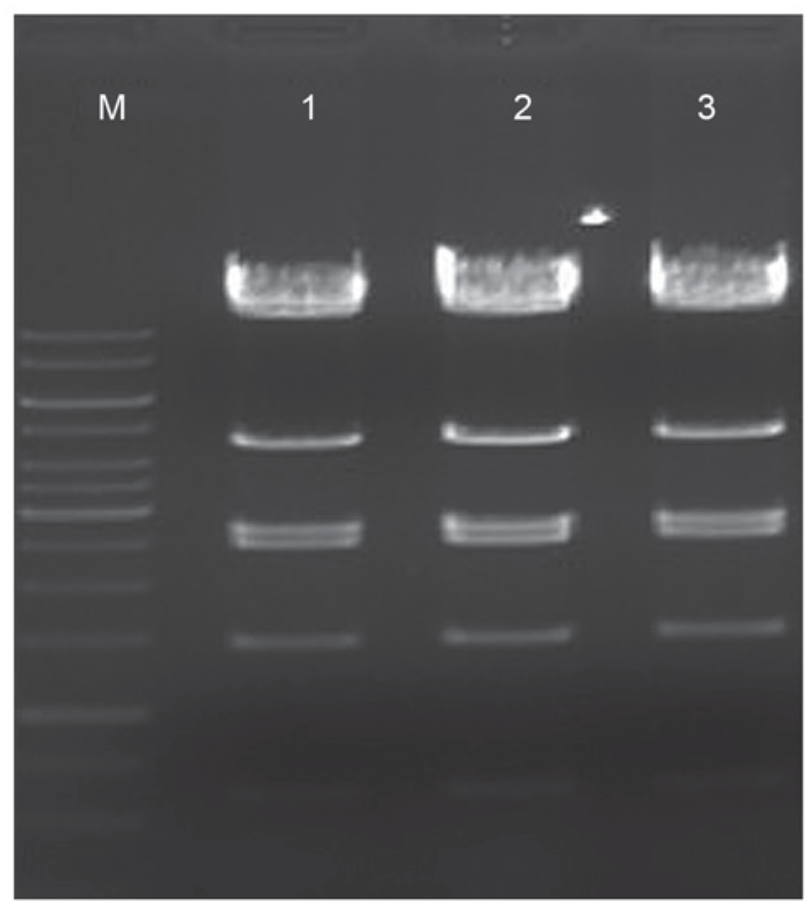

Figure 2. pAdxsi-green fluorescent protein-solute carrier family 7 member 8 sequencing results. Marker (1 kb DNA ladder); from top to bottom: $10 \mathrm{~kb}$, $8 \mathrm{~kb}, 6 \mathrm{~kb}, 5 \mathrm{~kb}, 4 \mathrm{~kb}, 3.5 \mathrm{~kb}, 3 \mathrm{~kb}, 2.5 \mathrm{~kb}, 2 \mathrm{~kb}, 1.5 \mathrm{~kb}, 1 \mathrm{~kb}, 750 \mathrm{bp}, 500 \mathrm{bp}$, $250 \mathrm{bp}$; lanes 1-3, three positive clones; from top to bottom: $14.5 \mathrm{~kb}, 11.7 \mathrm{~kb}$ $4.4 \mathrm{~kb}, 2.66 \mathrm{~kb}, 2.47 \mathrm{~kb}, 1.45 \mathrm{~kb}, 0.6 \mathrm{~kb}$ (7 specific bands following enzyme digestion).

the SLC7A8 gene, coding for the LAT2 dopamine uptake transporter, was revealed to be significantly upregulated in kidneys and second-order mesenteric arteries of SHR rats. The SLC7 gene family comprises two subfamilies, the cationic amino acid transporters, and the glycoprotein-associated amino acid transporters, also called light chain (16-18). SLC7A8 is a member of the SLC7 family and belongs to the light chain subfamily. SLC7A8 encodes two proteins, containing 531 and 535 amino acids, which are $92 \%$ identical.

A previous study by Pinho et al evaluated the uptake of L-DOPA in isolated renal proximal tubules of SHR and
WKY rats, and the expression of LAT1 and LAT2 in the renal cortex and intestinal mucosa was also investigated (19). Expression of LAT2 in the SHR renal cortex was increased compared with in WKY tissue, as detected by northern blotting. Tubular uptake of L-DOPA via LAT2 was revealed to be the rate-limiting step of renal dopamine synthesis, whereas uptake was increased in SHR compared with in WKY rats (19). It has previously been hypothesized that the overexpression of LAT2 in SHR renal tissue may contribute to the enhanced renal uptake of L-DOPA, which is organ-specific and precedes the onset of hypertension (20). The results of the present study indicated that overexpression of the SLC7A8 gene can increase the uptake of L-DOPA in renal cells. L-DOPA uptake progressively increased with increasing dose of SLC7A8 and incubation time. The present results are consistent with previous studies, as they demonstrated that by increasing the expression of SLC7A8 in tubular epithelial cells a corresponding increase in L-DOPA uptake could be achieved. L-type amino acid transporters are responsible for transporting neutral amino acids with high affinity $\left(\mathrm{K}_{\mathrm{m}}\right.$ in the $\mu \mathrm{M}$ range), independent of $\mathrm{Na}^{+}$concentration in the extracellular medium, whereas they also exhibit a particularly high capacity for trans-stimulation (21). NRK-52E cells can absorb L-DOPA through the $\mathrm{pH}$-dependent LAT2. This is further supported by the present results, demonstrating that L-DOPA uptake was markedly enhanced in NRK-52E cells transduced with the an adenoviral vector containing the SLC7A8 gene in order to upregulate the expression of the transporter. Therefore, it may be hypothesized that SLC7A8 serves an important role in the transportation and uptake of L-DOPA by renal cells.

The renal proximal tubule is the main site of L-DOPA decarboxylation and dopamine synthesis, indicating that the activity of LAT2 may limit the synthesis of renal dopamine (22). The $\mathrm{Na}^{+}$-independent transport systems of L-DOPA include system L (LAT1 and LAT2) and system $\mathrm{b}^{0,+}(23)$. LAT1 is primarily localized in brain capillary endothelial cells (24). The transporter system $b^{0,+}$ is a $\mathrm{Na}^{+}$-independent transporter for neutral and basic amino acids that also recognizes the di-amino acid cysteine (25). LAT2 is a $\mathrm{Na}^{+}$-independent transporter with a broad specificity for small and large neutral amino acids that is stimulated by acid $\mathrm{pH}$. The expression of LAT1 and LAT2 in SHR cells has been reported to differ significantly compared with in cells from WKY rats (20). LAT2 gene silencing markedly reduced the inward and outward transfer of $\left[{ }^{14} \mathrm{C}\right]-\mathrm{L}-\mathrm{DOPA}$, suggesting a major role of LAT2 in renal L-DOPA handling (26).

Following its synthesis in renal epithelial cells, dopamine can exert natriuretic and diuretic effects via activation of $\mathrm{D}_{1}$-like receptors located at various regions in the nephron. In proximal tubules, dopamine can increase $\mathrm{Na}^{+}$ excretion via inhibiting the main $\mathrm{Na}^{+}$transport mechanisms at the apical membranes of the tubular cells, i.e. the $\mathrm{Na}^{+} / \mathrm{K}^{+} /$ATPase and the $\mathrm{Na}^{+} / \mathrm{H}^{+}$exchanger (27). In SHR, dopamine $\mathrm{D}_{1}$-like receptor-mediated natriuretic and diuretic responses are decreased compared with in normotensive WKY rats (28).

Two limitations exist in the present study. Firstly, although the present results demonstrated that overexpression of the 
A

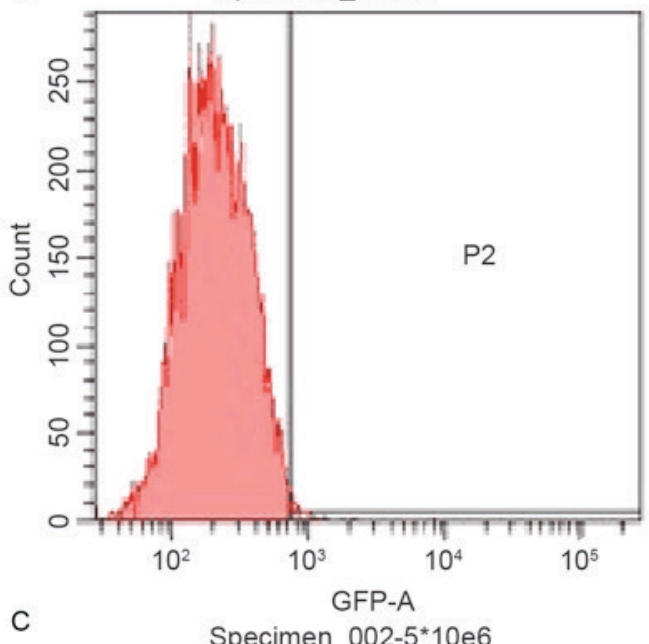

C

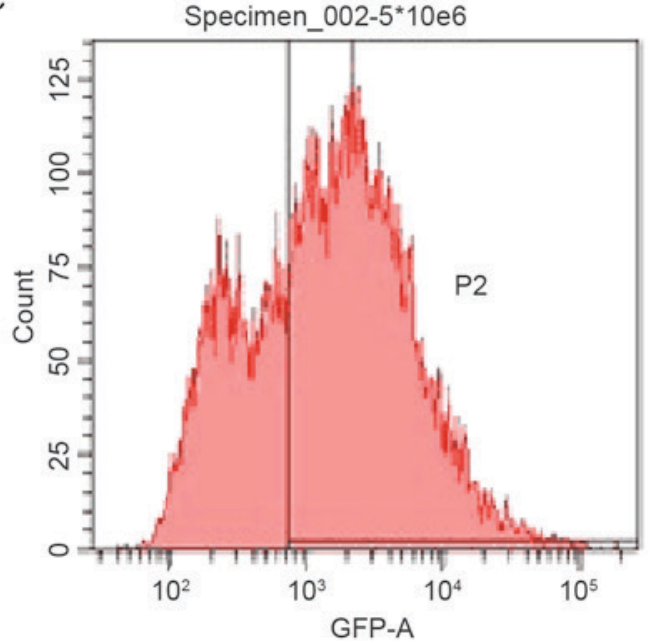

E

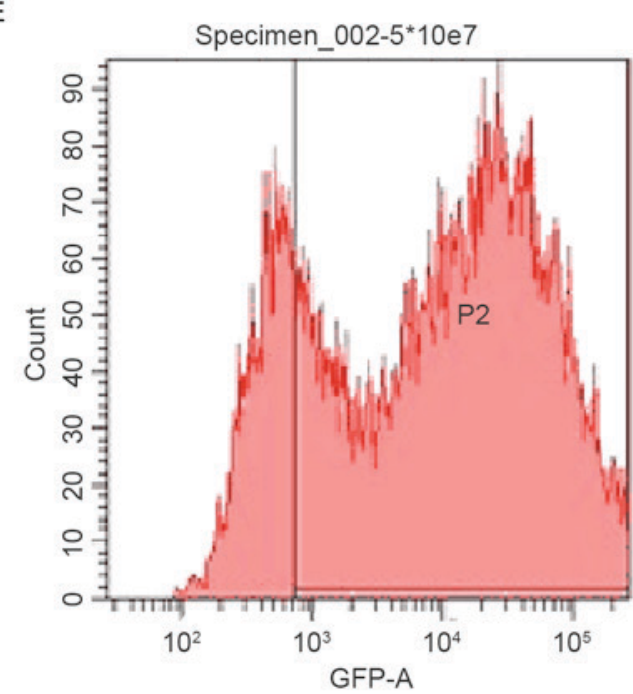

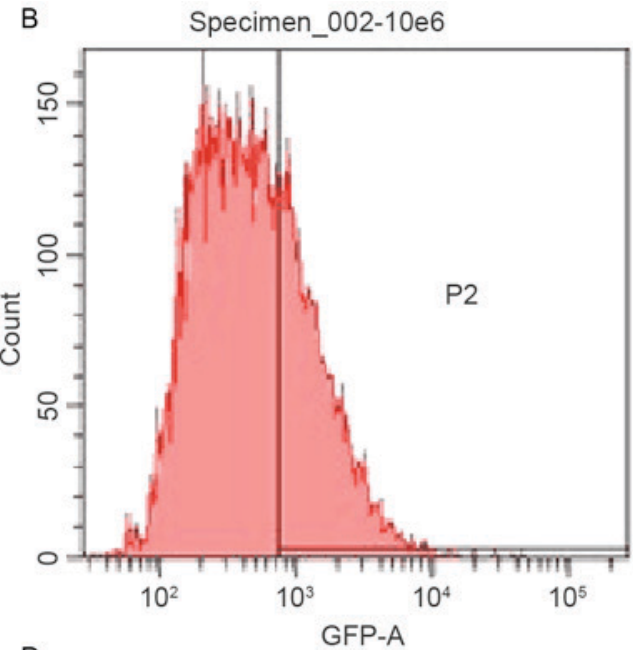

D

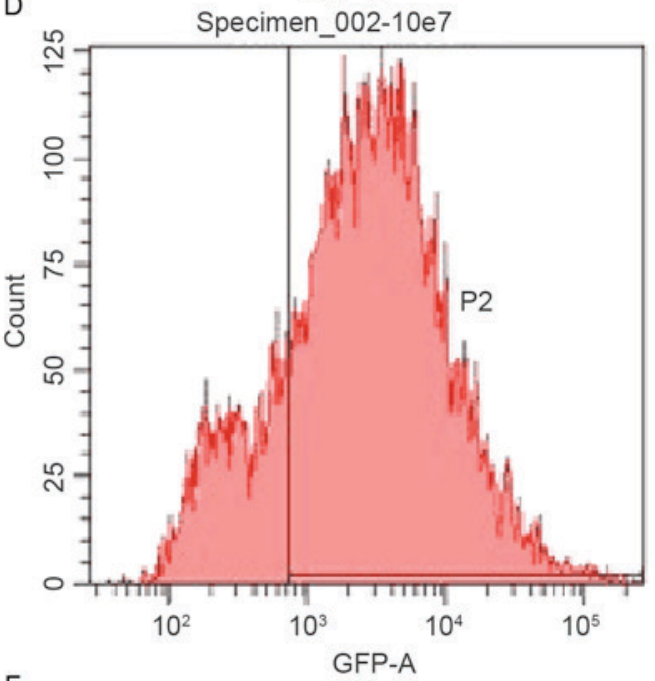

F

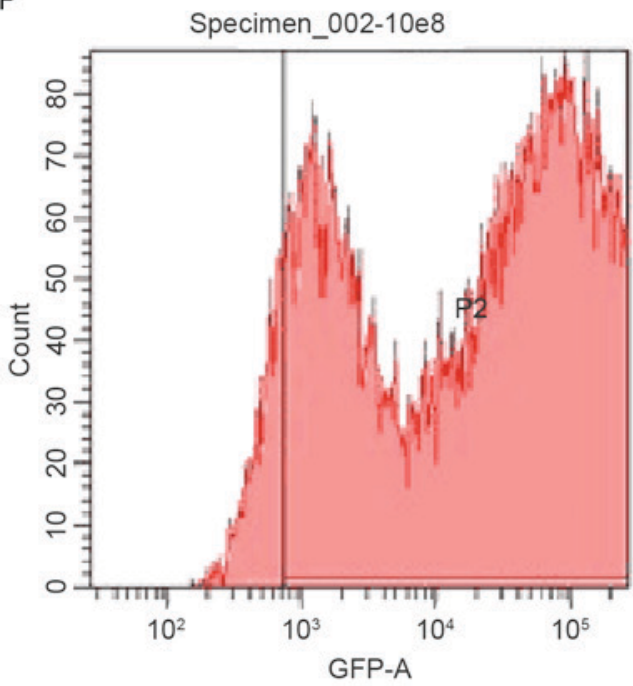

Figure 3. Transduction efficiency was assessed using flow cytometry. The efficiency of NRK-52E cell transduction for various viral titers was assessed using flow cytometry $48 \mathrm{~h}$ post-transduction. Transduction efficiency: (A) Blank, 0.6\%; (B) 1x106 PFU/ml, 32.6\%; (C) 5x10 PFU/ml, 68.4\%; (D) 1x107 PFU/ml, 80.8\%; (E) 5x10 ${ }^{7} \mathrm{PFU} / \mathrm{ml}, 82.3 \%$; (F) $1 \times 10^{8} \mathrm{PFU} / \mathrm{ml} 93.1 \%$. PFU, plaque-forming unit.

SLC7A8 gene can promote the uptake of L-DOPA in renal tubular epithelial cells, it remains to be elucidated whether increased SLC7A8 expression can promote dopamine synthesis. In addition, the lack of in vivo evidence supporting that SLC7A8 overexpression can promote the renal uptake of L-DOPA and subsequent blood pressure elevation further limits the impact of the present study. Further studies are required, including in vivo experiments, to elucidate the role of SLC7A8 in renal dopamine synthesis and its implication in blood pressure regulation.

In conclusion, the results of the present study indicated that SLC7A8 may serve a role in the onset and progression 

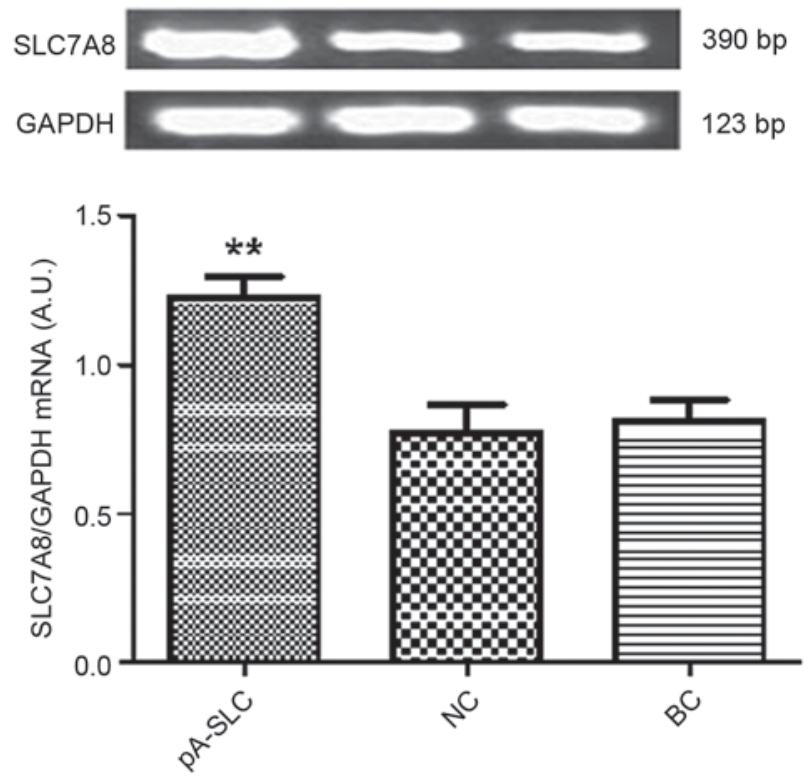

Figure 4. Transduction efficiency was assessed using reverse transcription-quantitative polymerase chain reaction. GAPDH was used as an internal control gene. Data are expressed as the mean \pm standard deviation. The experimental pA-SLC7A8 group was compared with the NC or BC group. ${ }^{* *} \mathrm{P}<0.01$ vs. $\mathrm{NC}$ and BC cells. SLC7A8, solute carrier family 7 member 8 ; $\mathrm{NC}$, negative control; BC, blank control.
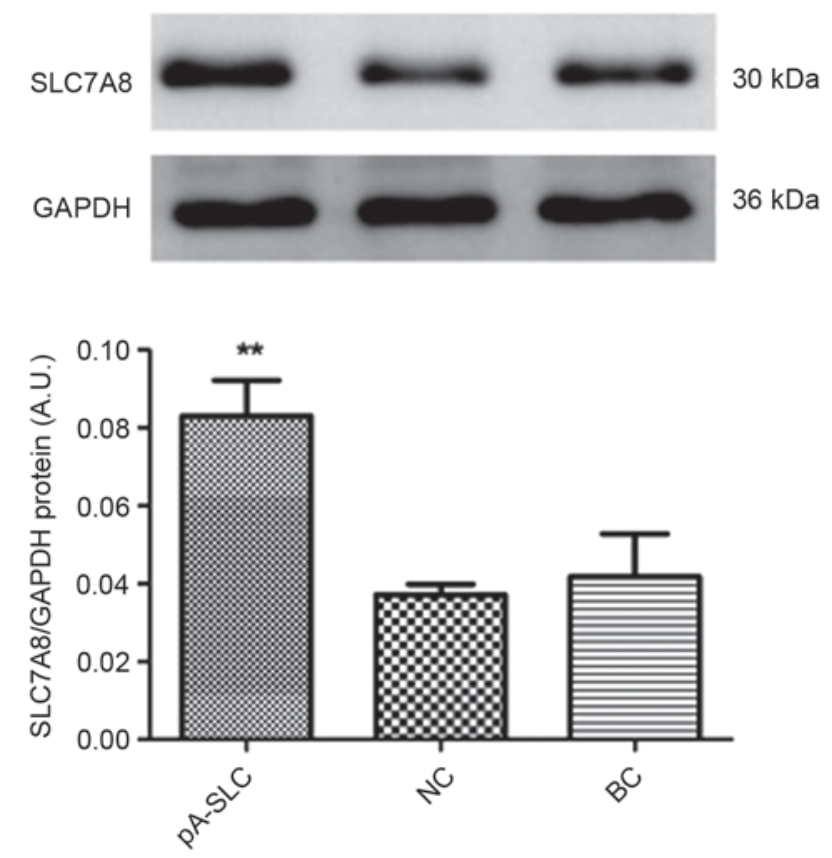

Figure 5. Transduction efficiency was assessed using western blot analysis. GAPDH was used as the internal reference. Data are expressed as the mean \pm standard deviation. The experimental pA-SLC7A8 group was compared with the $\mathrm{NC}$ or BC group. ${ }^{* *} \mathrm{P}<0.01$ vs. $\mathrm{NC}$ and BC cells. SLC7A8, solute carrier family 7 member 8 ; NC, negative control; BC, blank control.

of essential hypertension. Further studies, investigating the expression of SLC7A8 in vivo, and its association with the dopaminergic system, are required to elucidate its role in the regulation of blood pressure under various physiological and pathophysiological conditions, including essential hypertension.

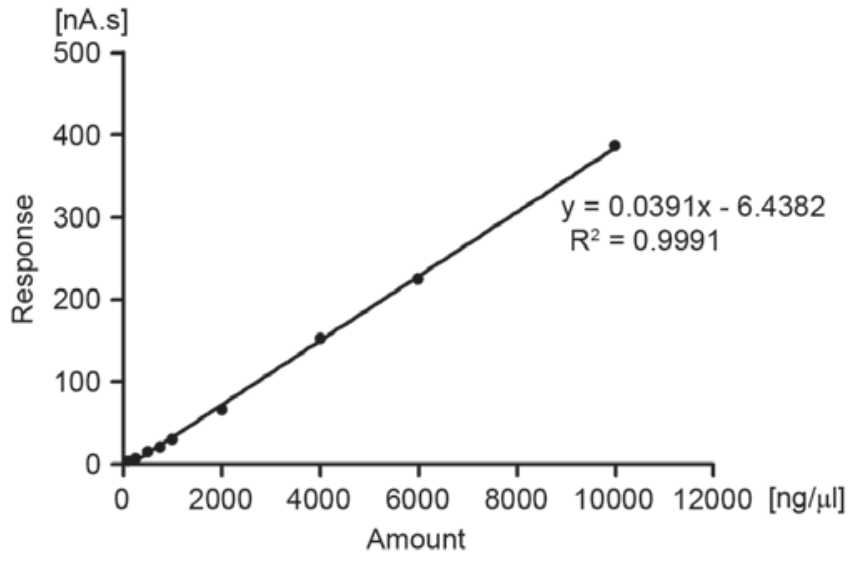

Figure 6. Standard curve for L-DOPA. Linear equation is $\mathrm{y}=0.0391 \mathrm{x}-6.4382$, $\mathrm{R}^{2}=0.9991$. The linear concentration range is $100-10,000 \mathrm{ng} / \mu 1$. L-DOPA, L-3,4-dihydroxyphenylalanine.

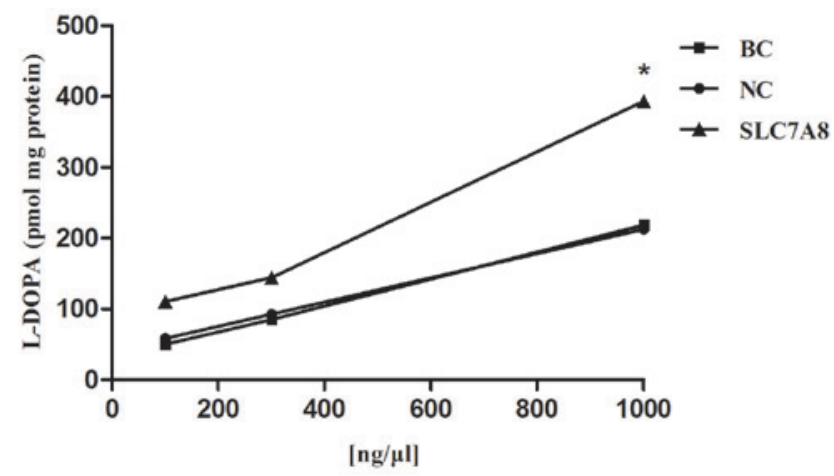

Figure 7. Dose-dependent uptake of L-DOPA. Cells were incubated with increasing doses of SLC7A8 alongside $300 \mu \mathrm{l}$ L-DOPA $(1 \mu \mathrm{g} / \mathrm{ml})$ for 6 min. Uptake was measured via high performance liquid chromatography. Compared with $\mathrm{BC}$ or $\mathrm{NC}$ groups, transduction with the recombinant adenoviral vector (pAdxsi-green fluorescent protein-SLC7A8) resulted in significantly increased L-DOPA uptake. ${ }^{*} \mathrm{P}<0.05$ vs. $\mathrm{NC}$ and $\mathrm{BC}$ cells. L-DOPA, L-3,4-dihydroxyphenylalanine; SLC7A8, solute carrier family 7 member 8; BC, blank control; NC, negative control.

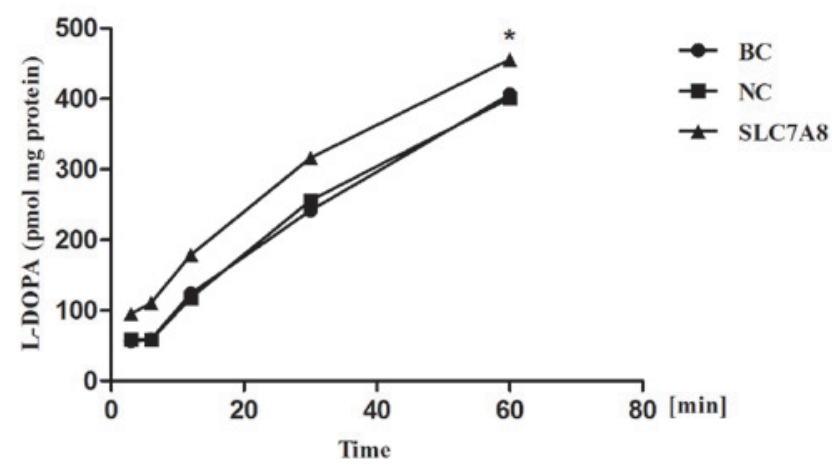

Figure 8. Time-dependent uptake of L-DOPA. Cells were incubated with $1,000 \mathrm{ng} / \mu 1 \mathrm{SLC} 7 \mathrm{~A} 8$ and $300 \mu 1 \mathrm{~L}-\mathrm{DOPA}(1 \mu \mathrm{g} / \mathrm{ml})$ for $3,6,12,30$ and $60 \mathrm{~min}$. Uptake was measured via high performance liquid chromatography. Compared with $\mathrm{BC}$ or $\mathrm{NC}$ groups, transduction with the recombinant adenoviral vector (pAdxsi-green fluorescent protein-SLC7A8) resuted in significantly increased L-DOPA uptake. ${ }^{*} \mathrm{P}<0.05$ vs. NC and BC cells L-DOPA, L-3,4-dihydroxyphenylalanine; BC, blank control; NC, negative control; SLC7A8, solute carrier family 7 member 8. 


\section{Acknowledgements}

The present study was supported by the Ministry of Health of the People's Republic of China Science Foundation (grant no. WKJ-ZJ-1420), and the Hangzhou Science and Technology Development Project (grant no. 20150633B05).

\section{References}

1. Sun H, Yang ZQ, Liu SY, Yu L, Huang K, Lin KQ, Chu JY and Huang XQ: Correlation between natriuretic peptide receptor $\mathrm{C}$ (NPR3) gene polymorphisms and hypertension in the Dai people of China. Genet Mol Res 14: 8786-8795, 2015.

2. Pinto V, Pinho MJ and Soares-da-Silva P: Renal amino acid transport systems and essential hypertension. FASEB J 27: 2927-2938, 2013.

3. Moura E, Silva E, Serrão MP, Afonso J, Kozmus CE and Vieira-Coelho MA: $\alpha 2$ C-Adrenoceptors modulate L-DOPA uptake in opossum kidney cells and in the mouse kidney. Am J Physiol Renal Physiol 303: F928-F938, 2012.

4. Camargo SM, Vuille-dit-Bille RN, Mariotta L, Ramadan T, Huggel K, Singer D, Götze O and Verrey F: The molecular mechanism of intestinal levodopa absorption and its possible implications for the treatment of Parkinson's disease. J Pharmacol Exp Ther 351: 114-123, 2014.

5. del Amo EM, Urtti A and Yliperttula M: Pharmacokinetic role of L-type amino acid transporters LAT1 and LAT2. Eur J Pharm Sci 35: 161-174, 2008.

6. Huang X, Wang B, Yang D, Shi X, Hong J, Wang S, Dai X, Zhou X and Geng YJ: Reduced expression of FXYD domain containing ion transport regulator 5 in association with hypertension. Int J Mol Med 29: 231-238, 2012.

7. Chen K, Deng K, Wang X, Wang Z, Zheng S, Ren H, He D, Han Y, Asico LD, Jose PA and Zeng C: Activation of D4 dopamine receptor decreases angiotensin II type 1 receptor expression in rat renal proximal tubule cells. Hypertension 65: 153-160, 2015.

8. Igreja B, Pires NM, Bonifácio MJ, Loureiro AI, Fernandes-Lopes C, Wright LC and Soares-da-Silva P: Blood pressure-decreasing effect of etamicastat alone and in combination with antihypertensive drugs in the spontaneously hypertensive rat. Hypertens Res 38: 30-38, 2015.

9. Vieira-Coelho MA, Serrão P, Hussain T, Lokhandwala MF and Soares-da-Silva P: Salt intake and intestinal dopaminergic activity in adult and old Fischer 344 rats. Life Sci 69: 1957-1968, 2001.

10. Livak KJ and Schmittgen TD: Analysis of relative gene expression data using real-time quantitative PCR and the 2(-Delta Delta C(T)) Method. Methods 25: 402-408, 2001

11. Wan TT, Li XF, Sun YM, Li YB and Su Y: Role of the calpain on the development of diabetes mellitus and its chronic complications. Biomed Pharmacother 74: 187-190, 2015.

12. Siklos M, BenAissa M and Thatcher GR: Cysteine proteases as therapeutic targets: Does selectivity matter? A systematic review of calpain and cathepsin inhibitors. Acta Pharm Sin B 5: 506-519, 2015.

13. Kawada N, Kristensen DB, Asahina K, Nakatani K, Minamiyama Y, Seki S and Yoshizato K: Characterization of a stellate cell activation-associated protein (STAP) with peroxidase activity found in rat hepatic stellate cells. J Biol Chem 276: 25318-25323, 2001.
14. Ostendorf T, Boor P, van Roeyen CR and Floege J: Plateletderived growth factors (PDGFs) in glomerular and tubulointerstitial fibrosis. Kidney Int Suppl (2011) 4: 65-69, 2014.

15. Leask A: Getting to the heart of the matter: New insights into cardiac fibrosis. Circ Res 116: 1269-1276, 2015.

16. Fotiadis D, Kanai Y and Palacin M: The SLC3 and SLC7 families of amino acid transporters. Mol Aspects Med 34: 139-158, 2013.

17. Schweikhard ES and Ziegler CM: Amino acid secondary transporters: Toward a common transport mechanism. Curr Top Membr 70: 1-281, 2012.

18. Closs EI, Boissel JP, Habermeier A and Rotmann A: Structure and function of cationic amino acid transporters (CATs). J Membr Biol 213: 67-77, 2006.

19. Pinho MJ, Gomes P, Serrão MP, Bonifácio MJ and Soares-da-Silva P: Organ-specific overexpression of renal LAT2 and enhanced tubular L-DOPA uptake precede the onset of hypertension. Hypertension 42: 613-618, 2003.

20. Pinho MJ, Serrão MP, Gomes P, Hopfer U, Jose PA and Soares-da-Silva P: Over-expression of renal LAT1 and LAT2 and enhanced L-DOPA uptake in SHR immortalized renal proximal tubular cells. Kidney Int 66: 216-226, 2004.

21. Soares-da-Silva P and Serrão MP: High- and low-affinity transport of L-leucine and L-DOPA by the hetero amino acid exchangers LAT1 and LAT2 in LLC-PK1 renal cells. Am J Physiol Renal Physiol 287: F252-F261, 2004.

22. Sizova D, Velazquez H, Sampaio-Maia B, Quelhas-Santos J, Pestana M and Desir GV: Renalase regulates renal dopamine and phosphate metabolism. Am J Physiol Renal Physiol 305: F839-F844, 2013.

23. Ishiia H, Sasaki Y, Goshima Y, Kanai Y, Endou H, Ayusawa D, Ono H, Miyamae T and Misu Y: Involvement of rBAT in $\mathrm{Na}(+)$-dependent and -independent transport of the neurotransmitter candidate L-DOPA in Xenopus laevis oocytes injected with rabbit small intestinal epithelium poly $\mathrm{A}(+) \mathrm{RNA}$. Biochim Biophys Acta 1466: 61-70, 2000.

24. Kageyama T, Nakamura M, Matsuo A, Yamasaki Y, Takakura Y, Hashida M, Kanai Y, Naito M, Tsuruo T, Minato N and Shimohama S: The 4F2hc/LAT1 complex transports L-DOPA across the blood-brain barrier. Brain Res 879: 115-121, 2000.

25. Gomes P and Soares-da-Silva P: Na+-independent transporters, LAT-2 and b0,+,exchange L-DOPA with neutral and basic amino acids in two clonal renal cell lines. J Membr Biol 186: 63-80, 2002.

26. Soares-Da-Silva P, Serrão MP, Pinho MJ and Bonifácio MJ: Cloning and gene silencing of LAT2, the L-3,4-dihydroxyphenylalanine (L-DOPA) transporter, in pig renal LLC-PK1 epithelial cells. FASEB J 18: 1489-1498, 2004.

27. Pinho MJ, Serrão MP and Soares-da-Silva P: High-salt intake and the renal expression of amino acid transporters in spontaneously hypertensive rats. Am J Physiol Renal Physiol 292: F1452-F1463, 2007.

28. Chen Y, Asico LD, Zheng S, Villar VA, He D, Zhou L, Zeng C and Jose PA: Gastrin and D1 dopamine receptor interact to induce natriuresis and diuresis. Hypertension 62: 927-933, 2013. 